\title{
During Transrectal Ultrasound-guided Prostate Biopsy Which Combination of Analgesia Method is Effective? A Prospective Randomized Study
}

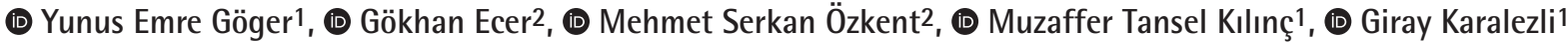 \\ ${ }^{1}$ Necmettin Erbakan University Meram Faculty of Medicine, Department of Urology, Konya, Turkiye \\ 2Konya City Hospital, Clinic of Urology, Konya, Turkiye
}

\section{What's known on the subject? and What does the study add?}

Transrectal ultrasound-guided prostate biopsy is the most commonly used procedure for the diagnosis of Prostate cancer. During prostate biopsy, it causes pain and anxiety in patients. Although it is a commonly used procedure, a standard method of analgesia has not been established. Although the combination of topical anesthesia and periprostatic nerve block is used frequently, it can sometimes be ineffective. In our prospective study, we evaluated factors such as probe insertion, prostate biopsy cores and local anesthetic administration, and prostate volume that affect pain in patients during biopsy. We aimed to find the most effective and comfortable analgesia combination for patients during prostate biopsy.

\begin{abstract}
Objective: This study aimed to evaluate the effectivity of pain palliation with intrarectal local anesthesia (IRLA), periprostatic nerve block (PPNB), apex nerve block (ANB), or their combination during transrectal ultrasound-guided (TRUS) prostate biopsy.

Materials and Methods: A total of 160 patients who underwent TRUS biopsy were included in this prospective study. Patients were divided into three groups randomly: IRLA group (group 1, n=40), PPNB + IRLA group (group 2, n=60), and ANB + PPNB + IRLA group (group 3, n=60). Visual analog scale (VAS) was used at three separate times during prostate biopsy: on insertion of the probe through the anal canal, during the administration of anesthesia, and during needle biopsy. The pain palliation of each method was compared among the groups.

Results: No significant difference was observed in demographic features among the groups. However, biopsy-related pain was the highest in group 1 for each core, followed by group 2 and group 3 ( $p<0.05$ for all core scores). The pain level felt with local anesthesia administration was higher in group 3 than in group 2 and the lowest in group $1(p<0.05)$. In addition, VAS scores were significantly higher in patients with large prostate, especially in apical cores.
\end{abstract}

Conclusion: In prostate biopsy, ANB was more effective in reducing pain. ANB in patients with large prostate is considered to increase patient satisfaction by decreasing pain scores, especially in apical cores.

Keywords: Transrectal ultrasound-guided prostate biopsy, periprostatic nerve block, apex nerve block, intrarectal local anesthesia

\section{Introduction}

Prostate cancer ( $\mathrm{PCa}$ ) has affected 1.1 million people in the last few years and is the most common cancer worldwide, in which $15 \%$ of the total cases occur in men, compared with $8 \%$ in new cases (1). Early diagnosis of PCa increases survival and decreases morbidity $(2,3)$. Therefore, rapid and early diagnosis of PCa by urologists is important to achieve successful treatment results $(4,5)$.

Prostate biopsy is the gold standard method in cancer diagnosis. The decision for prostate biopsy is based on the prostate-specific antigen (PSA) level, suspicious digital rectal examination (DRE), and/or imaging findings (6). At present, biopsy is performed in

Correspondence: Yunus Emre Göger MD, Necmettin Erbakan University Meram Faculty of Medicine, Department of Urology, Konya, Turkiye Phone: +90 (533) 4150753 E-mail: dr_yegoger@yahoo.com ORCID-ID: orcid.org/0000-0002-4480-9093

Received: 19.12 .2020

Accepted: 29.05.2021

Cite this article as: Göger YE, Ecer G, Özkent MS, Kılınç MS, Karalezli G. During Transrectal Ultrasound-guided Prostate Biopsy Which Combination of

Analgesia Method is Effective? A Prospective Randomized Study. J Urol Surg 2021;8(3):191-197.

๑Copyright 2021 by the Association of Urological Surgery / Journal of Urological Surgery published by Galenos Publishing House. 
three ways: transperineal, transrectal, and magnetic resonance imaging-targeted biopsy (6).

Transrectal ultrasound-guided (TRUS) prostate biopsy is the most commonly used procedure for $\mathrm{PCa}$ diagnosis. Systematic biopsy (8-16 cores) is recommended in TRUS prostate biopsy (7). In the present study, 12-core biopsies of the prostate were performed.

Most patients undergoing prostate biopsy perceive TRUS prostate biopsy as a physically and psychologically traumatic experience (8). If severe pain is felt during biopsy, an effective biopsy cannot be performed, the risk of complications may increase, and cancer diagnosis is missed (9). Thus, patient compliance during the procedure is very important. Optimal analgesia should be applied according to scientific findings before TRUS prostate biopsy.

In the literature, many methods have been described for optimal analgesia to the prostate, such as local blockade to the prostate, parenteral analgesia, or sedoanalgesia (10-13). However, the applicability of these methods in actual practice is difficult, and none has become standardized. The clinicians determine the most appropriate method based on their experience and the pain threshold of the patient. Studies have reported that local anesthetic agent application next to the nerve bundle provides good pain control during anesthesia infiltration with TRUS prostate biopsy (14). The European Association of Urology recommends the combination of topical anesthesia and periprostatic nerve block (PPNB) (6).

Thus, the primary aim of this study was to compare PPNB, apex nerve block (ANB), and intrarectal local anesthesia (IRLA) in terms of pain palliation during TRUS prostate biopsy. The secondary aim was to determine which cores are painful for the patient during biopsy and to investigate the efficacy of the analgesic methods.

\section{Materials and Methods}

This study included patients who underwent TRUS prostate biopsy between January 2018 and December 2020 because of elevated PSA scores or suspicious DRE findings. The exclusion criteria were as follows: age $\geq 80$ years, bleeding diathesis, anticoagulant use, metastatic cancer, cognitive function impairment that hindered filling out of the visual analog scale (VAS), rectal and/or anal pathology, previous use of an analgesic drug, patients with PCa having perineural invasion, history of prostate surgery, and biopsy with more than 12 cores. Informed consent was obtained from the patients participating in the study.

The participants, 160 in total, of this study were divided into three groups: group 1 consisted of 40 patients who were administered IRLA, group 2 of 60 patients who received PPNB + IRLA, and group 3 of 60 patients received ANB + PPNB + IRLA. Patients were included indiscriminately into group 1, followed by group 2, and then group 3 . VAS was used to evaluate pain. Pain severity was assessed based on the 1-10-point VAS. While patients were undergoing a 12-core prostate biopsy, pain scores were obtained at three different times for each group: during probe placement through the anal canal, LA administration, and biopsy. During biopsy, pain was recorded as VAS scores according to the biopsy cores. Data were recorded at the end of the procedure, and each patient was asked whether they would like to undergo another biopsy.

In IRLA, a lubricant gel suspension containing $12.5 \mathrm{~g}$ of $1 \%$ lidocaine was directly squeezed into the rectum through the anus. In the left lateral decubitus position, a TRUS probe (BK Pro-Focus Ultrasound Scanner) was inserted into the patients' rectum to calculate the prostate volume (PV) in the longitudinal and transverse planes, and their ultrasonographic views were examined. The same amount of local analgesia was applied to groups 2 and 3, regardless of the PV of the patients.

In PPNB, the triangle between the prostate base and the seminal vesicle was visualized with TRUS support, and a total of $10 \mathrm{~mL}$ of $1 \%$ lidocaine hydrochloride $(5 \mathrm{~mL}$ each on the right side and left side) was injected into the area where both neurovascular bundles are located. The Denonvilier fascia was separated during the injection, and the anesthetic agent filled into the tissue.

In $A N B, 10 \mathrm{~mL}$ of $1 \%$ lidocaine hydrochloride $(5 \mathrm{~mL}$ each on the right side and left side) was injected into the apical region of the prostate's surrounding apex. The biopsy procedure was initiated $5 \mathrm{~min}$ after the application of the local anesthetic agent. All patients received an antibiotic (Ciprofloxacin $500 \mathrm{mg}$ ) for prophylaxis. Moreover, 18-gage automatic tru-cut biopsy needles (Geotec ESTACORE ${ }^{\circledR}$ ) compatible with the ultrasound probe were used in the biopsy. The ultrasonography image was aligned with the line guide showing the expected path of the needle, the biopsy needle was advanced $0.5 \mathrm{~cm}$, and a sample from $1.5-\mathrm{cm}$ tissue was taken. The biopsy specimen obtained was added with 10\% formol and sent separately for pathological examination.

Ethics committee approval was obtained from the local ethics committee of our tertiary center (2020/2463).

\section{Statistical Analyses}

SPSS 23.0 (IBM Corp. Armonk, NY, USA) program was used to analyze the obtained data. Categorical variables are shown as frequency and percentage, and continuous variables are presented as average values. Chi-square analysis was used for categorical variables, the independent t-test and MannWhitney $\mathrm{U}$ test were used to compare two groups of continuous 
variables, and Kruskal-Wallis analysis was employed to compare more than two groups. The analysis of variance test was used to calculate the significance of the difference between the means of multiple independent data. In all evaluations, $p<0.05$ was considered the significant threshold level.

\section{Results}

In this study, the mean age of the patients was $64.3 \pm 7.6$ years, the mean PV was $48.18 \pm 17.1 \mathrm{~mL}$, and the mean PSA level was $19.6 \pm 3.4 \mathrm{ng} / \mathrm{mL}$. No significant difference in demographic data was found (Table 1).

In this study, during the insertion of the ultrasound probe into the rectum, the mean VAS scores were 2.56, 2.54, and 2.75 in group 1, group 2, and group 3, respectively. No significant difference was noted among the groups $(p=0.44)$.

Moreover, the average VAS scores for groups 1, 2, and 3 were $3.205,2.24$, and 1.52 , respectively, which was significantly higher in group $1(p<0.05)$. Table 2 shows the VAS scores measured separately for each core. The average VAS score in group 1 cores was $>3$, and there was a moderate pain score (i.e., 3.205, 2.24, and 1.52). In groups 2 and 3 , a significant difference was noted among the cores, but the VAS pain score indicated generally mild pain. In groups 2 and 3 , the greatest difference was found between apical core biopsies (2.24 vs $1.52 ; p<0.05$ for all apex cores) (Table 2, Figure 1).

In terms of pain level felt during LA, the mean VAS score of group 2 was 2.7 and that of group 3 was $3.55(p<0.05)$.

After the procedure, $58.3 \%$ of the patients in group 1, 91\% in group 2, and 94.6\% in group 3 were affirmative to the question "Would you like to have another biopsy?" (group 1 vs group 2, $p<0.05$; group 1 vs group $3, p<0.05$; group 2 vs group $3, p=0.84$ ).

As a subgroup analysis, we investigated the effect of PV on VAS scores regardless of the group. The mean PV of the patients was $48.18 \mathrm{~mL}$. When the patients were categorized according to their PV as $<48.1 \mathrm{~mL}$ and $>48.1 \mathrm{~mL}$, 80 patients had prostate

\begin{tabular}{|l|l|l|l|l|}
\hline \multicolumn{5}{|l|}{ Table 1. Demographic features of the patients } \\
\hline Demographic features & $\begin{array}{l}\text { Group 1 } \\
\text { (mean + SD) }\end{array}$ & $\begin{array}{l}\text { Group 2 } \\
\text { (mean + SD) }\end{array}$ & $\begin{array}{l}\text { Group 3 } \\
\text { (mean + SD) }\end{array}$ & $\begin{array}{l}\text { p } \\
\mathbf{1 / 2 / 3}\end{array}$ \\
\hline Age (mean \pm SD) & $65.58 \pm 8.1$ & $66.29 \pm 8.7$ & $61.82 \pm 5.3$ & 0.183 \\
\hline PSA (mean \pm SD) & $20.09 \pm 7.3$ & $12.20 \pm 2.3$ & $26.91 \pm 7.2$ & 0.172 \\
\hline Prostate volume (mL) (mean \pm SD) & $49.31 \pm 15.2$ & $48.84 \pm 16.8$ & $46.79 \pm 18.5$ & 0.740 \\
\hline $\begin{array}{l}\text { VAS score on insertion of the ultrasound probe into } \\
\text { the rectum (mean } \pm \text { SD) }\end{array}$ & $2.56 \pm 1.3$ & $2.54 \pm 0.6$ & $2.75 \pm 0.9$ & 0.441 \\
\hline VAS score upon injection of local anesthesia (mean) & 0 & 2.70 & 3.55 & $p<0.05$ \\
\hline VAS scores (mean) & 3.20 & 2.24 & 1.52 & $p<0.05$ \\
\hline Would you give your consent for another biopsy? & & & & \multirow{2}{*}{$p<0.05$} \\
\hline Yes & $21(58.3 \%)$ & $51(91 \%)$ & $53(94.6 \%)$ & \\
\hline No & $15(41.7 \%)$ & $5(9 \%)$ & $3(5.4 \%)$ & \\
\hline VAS: Visual analog scale, SD: Standard deviation, PSA: Prostate-specific antigen & & & \\
\hline
\end{tabular}

\begin{tabular}{|l|l|l|l|l|}
\hline Table 2. Mean visual analog scale scores of the patients according to groups \\
\hline Prostate biopsy cores & Group 1 & Group 2 & Group 3 & p-value \\
\hline Right basal medial & $2.33 \pm 0.8$ & $1.52 \pm 0.6$ & $1.18 \pm 0.5$ & $<0.05$ \\
\hline Right basal lateral & $2.50 \pm 1.5$ & $1.57 \pm 0.8$ & $1.25 \pm 0.5$ & $<0.05$ \\
\hline Right mid-gland medial & $3.31 \pm 1.6$ & $1.86 \pm 0.7$ & $1.48 \pm 0.8$ & $<0.05$ \\
\hline Right mid-gland lateral & $3.06 \pm 1.6$ & $1.88_{ \pm} 0.7$ & $1.50 \pm 0.7$ & $<0.05$ \\
\hline Right apex medial & $4.33 \pm 1.8$ & $2.91 \pm 1.4$ & $1.84 \pm 1.0$ & $<0.05$ \\
\hline Right apex lateral & $4.36 \pm 1.8$ & $3.00 \pm 1.5$ & $1.89 \pm 0.7$ & $<0.05$ \\
\hline Left basal medial & $2.25 \pm 0.9$ & $1.55_{ \pm} 0.6$ & $1.34 \pm 0.4$ & $<0.05$ \\
\hline Left basal lateral & $2.14 \pm 0.9$ & $1.59 \pm 0.8$ & $1.30 \pm 0.5$ & $<0.05$ \\
\hline Left mid-gland medial & $3.03 \pm 1.6$ & $2.27 \pm 0.9$ & $1.50 \pm 0.6$ & $<0.05$ \\
\hline Left mid-gland lateral & $2.78 \pm 1.5$ & $2.09 \pm 0.7$ & $1.48 \pm 0.7$ & $<0.05$ \\
\hline Left apex medial & $431 \pm 1.6$ & $3.34 \pm 1.4$ & $1.95 \pm 1$ & $<0.05$ \\
\hline Left apex lateral & $4.06 \pm 16$ & $3.30 \pm 1.7$ & $1.90 \pm 1$ & $<0.05$ \\
\hline
\end{tabular}




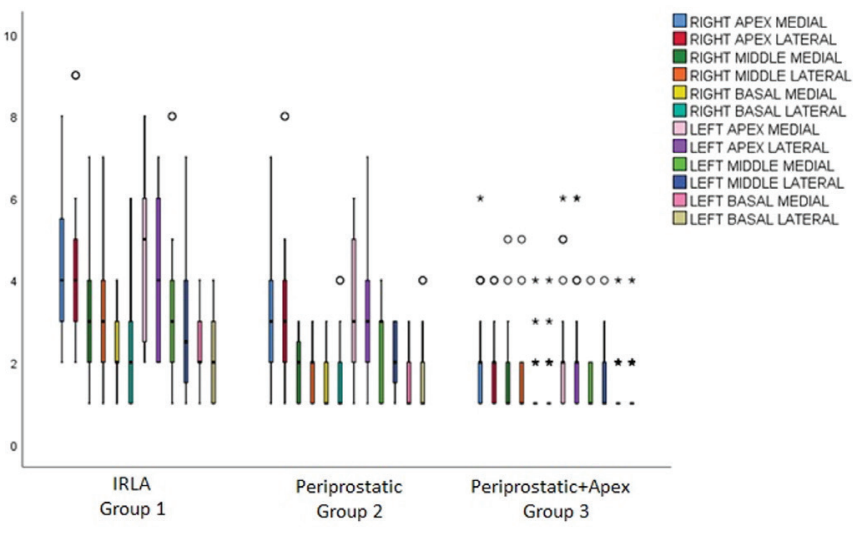

Figure 1. Visual analog scale score changes among the groups

\begin{tabular}{|c|c|c|c|}
\hline Prostate biopsy cores & $<48 \mathrm{~mL}$ & $>48 \mathrm{~mL}$ & p-value \\
\hline Right basal medial & 1.61 & 1.56 & 0.69 \\
\hline Right basal lateral & 1.56 & 1.81 & 0.17 \\
\hline Right mid-gland medial & 1.94 & 2.22 & 0.18 \\
\hline Right mid-gland lateral & 1.94 & 2.12 & 0.35 \\
\hline Right apex medial & 2.54 & 3.22 & 0.015 \\
\hline Right apex lateral & 2.54 & 3.31 & 0.005 \\
\hline Left basal medial & 1.61 & 1.56 & 0.74 \\
\hline Left basal lateral & 1.48 & 1.69 & 0.12 \\
\hline Left mid-gland medial & 1.98 & 2.38 & 0.05 \\
\hline Left mid-gland Lateral & 1.84 & 2.16 & 0.08 \\
\hline Left apex medial & 2.79 & 3.35 & 0.03 \\
\hline Left apex lateral & 2.69 & 3.35 & 0.01 \\
\hline
\end{tabular}

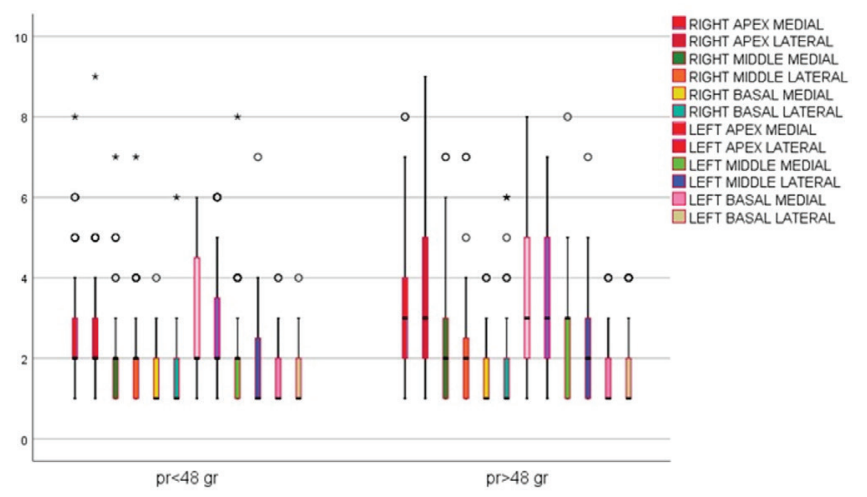

Figure 2. Change in visual analog scale score according to the prostate volume

$<48.1 \mathrm{~mL}$, and 68 patients had $>48.1 \mathrm{~mL}$ (Table 3, Figure 2). Those who had PV above the mean had significantly high VAS score pain in the right apex medial, right apex lateral, left apex medial, and left apex lateral $(p=0.015, p=0.005, p=0.018, p=0.04$, respectively). No significant difference was found among other cores. When PV and VAS pain scores were compared, the pain was generally mild in both groups, and comparable results were obtained.

In this study, one patient in group 1 and two patients each in group 2 and group 3 had urinary retention. Moreover, one patient in group 1, two patients in group 2, and one patient in group 3 had a fever. All these patients received medical treatment.

\section{Discussion}

In this study, the pain level experienced by the patients was measured not only during LA before TRUS prostate biopsy, but also for each core separately. Thus, the effectiveness of each LA providing the best analgesia for the separate cores was determined. This prospective study determined that PPNB + ANB significantly reduced pain not only in apical cores but also in all cores. However, in this group, more pain was experienced by the patients.

TRUS prostate biopsy is the standard procedure for the diagnosis of PCa in urological practice. Studies have reported that an increasing number of biopsies is accompanied by more severe pain and discomfort $(6,7)$. In a systematic biopsy, an extended pattern, at least a 12-core biopsy is recommended (sextant medial and lateral peripheral zones and lesion directed) by the board $(7,15)$. In this respect, in our urology clinic, prostate biopsy from at least 12 cores is the standard procedure.

In many reviews, significant differences were reported in pain perception in patients during prostate biopsy $(14,16,17)$; especially, the VAS score indicated not severe pain (VAS of 7-10). Even in control groups, the VAS score rarely comes to an intermediate level. However, when the patients were asked whether they would like to have a biopsy again, a positive response was significant in the analgesic groups. This finding indicates that patients' anxiety from pain is reduced. However, the more effectively the pain is reduced, the less anxiety is evident $(12,17)$.

Two factors are generally responsible for the pain that occurs during biopsy. First, the pain that occurs during the insertion of the ultrasound probe is caused by the stretching of the anal muscle fibers, which is attributed to IRLA's anal muscle fiber local relaxation and lubricant effect. It is an important advantage of being non-invasive. Ozveri et al. (18) described the pain between moderate and intolerable in 50\% of the patients who did not undergo IRLA before biopsy. In a meta-analysis, IRLA is thought to decrease pain when compared with the control group (12). However, the effect of IRLA on pain during the biopsy is controversial. A study supported that IRLA alone does not affect pain during biopsy (9). In general, IRLA was not 
the ideal type of anesthesia because it apparently could not eliminate pain during prostate biopsy.

The second cause of pain is needle insertion during a prostate biopsy. During biopsy, PPNB was more effective at reducing pain than IRLA (12). Seymour et al. (19) stated that PPNB causes a "bee sting"-like feeling. Moreover, lzol et al. (20) and Addla et al. (21) reported that LA administration in TRUS biopsy is simple and tolerable and reduces pain, and they recommend it during biopsy. In the present study, the patients did not feel any severe pain during PPNB.

Although PPNB causes pain relief during biopsy, it does not affect pain caused by the insertion of the transrectal probe and its movements in the rectum. Moreover, inferolateral prostate nerves should pass close to the rectal wall and local absorption from the anal mucosa should be rapid. PPNB + IRLA generates less pain during probe manipulation and less pain in the rectal wall and prostate during biopsy. As a result, IRLA + PPNB provides better pain control than IRLA alone $(22,23)$. In this study, when IRLA was compared with IRLA + PPNB, significant differences were found in the VAS scores in all cores. Some cores demonstrated mild to moderate differences.

ANB is applied during biopsy for two reasons: blockage of periprostatic sensory nerves that cross the apex and blockage of the pain nerves coming from the rectum (12). However, studies that have compared PPNB with ANB + PPNB are scarce and have controversial results. In a previous study of 60 patients, Khurana et al. (24) divided these patients according to the area where the LA was administered: apical region (group 1), bilateral basolateral region (group 2), and unilateral basolateral region (group 3). They found that the least pain was recorded in the group that received ANB, followed by the basolateral region. By contrast, another study found no significant difference in pain scores of patients undergoing PPNB and ANB (16). In the present study, unlike other studies, we compared IRLA alone with IRLA + PPNB + ANB and found a moderate difference in VAS scores in all cores. Between group 2 and group 3, an average difference of 1-2 points in VAS scores was noted in basal and middle cores, showing a significant difference. The most important difference was detected in apical core biopsies. It was effective in reducing pain during apical biopsies. One of the results of our study, except for the apical cores, is the decrease in the VAS scores (even if it is low) during biopsy in other cores. We think that with ANB, the LA administered in the prostate and rectal mucosa increases the blockage of pain nerves, and the efficiency of the periprostatic block is increased. Moreover, ANB is found to be effective; during ANB, ultrasonography revealed a crest under the mucosa and around the apex. This important finding is reflected in our results.
Unlike other studies, we evaluated VAS scores during LA injection. Especially, in ANB, the pain was significantly higher, but when the patients were asked on having a biopsy again, they provided a positive response, and this finding was significant in groups 2 and 3 . In the present study, as the number of local anesthetics increases, pain does increase. Informing patients about the pain that will occur during LA will be beneficial in reducing the patient's anxiety and pain. In addition, the lack of difference in response to re-biopsy between groups 2 and 3 may be related to the lack of VAS score difference between other cores, except for apical cores.

The relationship between PV and pain has not been defined clearly in previous studies. Turgut et al. (25) could not define a relationship between PV and pain during TRUS prostate biopsy. Yun et al. (26) stated that patients with larger PVs felt more pain during TRUS prostate biopsy. Additionally, Bingqian et al. (27) showed that IRLA and PPNB might be more beneficial in patients with PV $>48 \mathrm{~mL}$. Giannari et al. (28) stated that patients aged $<65$ years with $\mathrm{PV}>49 \mathrm{~mL}$ are more susceptible to pain and should receive anesthesia.

In our subgroup analysis, we evaluated PV, and our average PV is comparable with those of other studies. In this study, we investigated the difference in VAS scores between cores during biopsy according to the mean PV values. Statistically, we noticed a difference between apical cores but not in other cores. Thus, we can interpret that performing ANB in large prostate may reduce pain in apical core biopsies compared with small prostate. Moreover, studies evaluating the effectiveness of PV and ANB on pain during prostate biopsy are needed.

During prostate biopsy, lidocaine, prilocaine, and rubivacaine are the most frequently used local anesthetic agents in PPNB and ANB. Although used in different doses in various studies, generally, 5 or $10 \mathrm{~mL}$ of $1 \%$ lidocaine injection is preferred $(12,29)$. In the present study, $5 \mathrm{~mL}$ of $1 \%$ lidocaine was used for each prostate lobe to maintain homogeneity. No serious complications were reported in a meta-analysis comparing PPNB with IRLA (17). Comparable rates in fever and urinary retention were observed in both groups. The combined use of IRLA, PPNB, and ANB was considered safe. In the present study, no difference was found among the groups in terms of complications.

In a meta-analysis, pain during prostate biopsy varies between mild and moderate levels, even in the placebo groups when assessed by VAS scores. Severe pains are not seen. However, it is important to reduce patient anxiety as well as pain in the prostate biopsy and to biopsy the PCa zone. Biopsy should be performed carefully from the prostate posterior, lateral, and apex peripheral regions. Effective anesthesia of these sensitive areas can potentially reduce pain; it is not only convenient to the patient but also to urologists because they have the opportunity 
to perform multiple and effective biopsies. In the present study, we recommend performing ANB with IRLA + PPNB.

\section{Study Limitations}

This study has some limitations. First, since the focus was pain, heterogeneity cannot be ignored. Second, unlike other studies, although pain was investigated for each core, no sufficient evidence for an optimum analgesic method could be found. Finally, no detailed perception of pain development with the increase of cores could be obtained. Thus, more prospective studies with good methodology are needed for the pain experienced in the diverse cores.

\section{Conclusion}

In this prospective and randomized study, to reveal the difference among blockage methods, each stage of TRUS prostate biopsy starting with probe insertion, prostate biopsy cores, and local anesthetic application was evaluated. As the number of local anesthetics increases, pain becomes severe, especially during ANB. However, IRLA + PPNB + ANB is considered to provide the best analgesia in all cores.

\section{Ethics}

Ethics Committee Approval: Ethics committee approval was obtained from the local ethics committee of our tertiary center (2020/2463).

Informed Consent: Informed consent was obtained from the patients participating in the study.

Peer-review: Internally peer-reviewed.

\section{Authorship Contributions}

Surgical and Medical Practices: Y.E.G., M.T.K., Concept: Y.E.G., M.S.Ö., M.T.K., G.K., Design: Y.E.G., M.S.Ö., G.K., Data Collection or Processing: Y.E.G., G.E., M.S.Ö., M.T.K., Analysis or Interpretation: Y.E.G., M.S.Ö., G.K., Literature Search: Y.E.G., G.E., G.K., Writing: Y.E.G., G.E.

Conflict of Interest: No conflict of interest was declared by the authors.

Financial Disclosure: The authors declare that they have no relevant financial.

\section{References}

1. Ferlay J, Soerjomataram I, Dikshit R, Eser $S$, Mathers $C$, Rebelo M, Parkin DM, Forman D, Bray F. Cancer incidence and mortality worldwide: sources, methods and major patterns in GLOBOCAN 2012. Int J Cancer 2015;136:E359-386.

2. Hodge KK, McNeal JE, Stamey TA. Ultrasound guided transrectal core biopsies of the palpably abnormal prostate. J Urol 1989;142:66-70.
3. Brown AM, Elbuluk O, Mertan F, Sankineni S, Margolis DJ, Wood BJ, Pinto PA, Choyke PL, Turkbey B. Recent advances in image-guided targeted prostate biopsy. Abdom Imaging 2015;40:1788-1799.

4. Carroll PR, Parsons JK, Andriole G, Bahnson RR, Castle EP, Catalona WJ, Dahl DM, Davis JW, Epstein JI, Etzioni RB, Farrington T, Hemstreet GP 3rd, Kawachi MH, Kim S, Lange PH, Loughlin KR, Lowrance W, Maroni P, Mohler J, Morgan TM, Moses KA, Nadler RB, Poch M, Scales C, Shaneyfelt TM, Smaldone MC, Sonn G, Sprenkle P, Vickers AJ, Wake R, Shead DA, FreedmanCass DA. NCCN Guidelines Insights: Prostate Cancer Early Detection, Version 2.2016. J Natl Compr Canc Netw 2016;14:509-519.

5. van den Bergh RCN, Loeb S, Roobol MJ. Impact of Early Diagnosis of Prostate Cancer on Survival Outcomes. Eur Urol Focus 2015;1:137-146.

6. Mottet $N$, Bellmunt J, Bolla M, Briers E, Cumberbatch MG, De Santis $M$, Fossati N, Gross T, Henry AM, Joniau S, Lam TB, Mason MD, Matveev VB, Moldovan PC, van den Bergh RCN, Van den Broeck T, Van der Poel HG, Moldovan PC, Van der Kwast TH, Rouviere O, Schoots IG, Wiegel T, Cornford P. EAU-ESTRO-ESUR-SIOG guidelines on prostate cancer. Eur Urol 2016;71:618-629.

7. Ukimura O, Coleman JA, de la Taille A, Emberton M, Epstein Jl, Freedland SJ, Giannarini G, Kibel AS, Montironi R, Ploussard G, Roobol MJ, Scattoni $V$, Jones JS. Contemporary role of systematic prostate biopsies: indications, techniques, and implications for patient care. Eur Urol 2013;63:214-230.

8. Bastide C, Lechevallier E, Eghazarian C, Ortega JC, Coulange C. Tolerance of pain during transrectal ultrasound-guided biopsy of the prostate: risk factors. Prostate Cancer Prostatic Dis 2003;6:239-241.

9. Tiong HY, Liew LC, Samuel M, Consigliere D, Esuvaranathan K. A metaanalysis of local anesthesia for transrectal ultrasound-guided biopsy of the prostate. Prostate Cancer Prostatic Dis 2007;10:127-136.

10. Autorino R, De Sio M, Di Lorenzo G, Damiano R, Perdonà S, Cindolo L, D'Armiento M. How to decrease pain during transrectal ultrasound guided prostate biopsy: a look at the literature. J Urol 2005;174:2091-2097.

11. Maccagnano $C$, Scattoni $V$, Roscigno $M$, Raber $M$, Angiolilli $D$, Montorsi F, Rigatti P. Anaesthesia in transrectal prostate biopsy: which is the most effective technique? Urol Int 2011;87:1-13.

12. Yang Y, Liu Z, Wei Q, Cao D, Yang L, Zhu Y, Wei X, Tang Z, Liu L, Han P. The Efficiency and Safety of Intrarectal Topical Anesthesia for Transrectal Ultrasound-Guided Prostate Biopsy: A Systematic Review and MetaAnalysis. Urol Int 2017;99:373-383.

13. Tobias-Machado $M$, Verotti MJ, Aragao AJ, Rodrigues AO, Borrelli $M$, Wroclawski ER. Prospective randomized controlled trial comparing three different ways of anesthesia in transrectal ultrasound-guided prostate biopsy. Int Braz J Urol 2006;32:172-180.

14. Trucchi A, De Nunzio C, Mariani S, Palleschi G, Miano L, Tubaro A. Local anesthesia reduces pain associated with transrectal prostatic biopsy. A prospective randomized study. Urol Int 2005;74:209-213.

15. Presti JC Jr, O'Dowd GJ, Miller MC, Mattu R, Veltri RW. Extended peripheral zone biopsy schemes increase cancer detection rates and minimize variance in prostate specific antigen and age related cancer rates: results of a community multi-practice study. J Urol 2003;169:125-129.

16. Cevik I, Dillioglugil O, Zisman A, Akdas A. Combined "periprostatic and periapical" local anesthesia is not superior to "periprostatic" anesthesia alone in reducing pain during Tru-Cut prostate biopsy. Urology 2006;68:12151219.

17. Garcia-Perdomo HA, Mejia NG, Fernandez L, Carbonell J. Effectiveness of periprostatic block to prevent pain in transrectal prostate biopsy: a systematic review and a network meta-analysis. Cent European J Urol 2019;72:121-133.

18. Ozveri H, Cevik I, Dillioglugil 0, Akdaş A. Transrectal periprostatic lidocaine injection anesthesia for transrectal prostate biopsy: a prospective study. Prostate Cancer Prostatic Dis 2003;6:311-314. 
19. Seymour H, Perry MJ, Lee-Elliot C, Dundas D, Patel U. Pain after transrectal ultrasonography-guided prostate biopsy: the advantages of periprostatic local anaesthesia. BJU Int 2001;88:540-544.

20. Izol V, Soyupak B, Seydaoglu G, Aridogan IA, Tansug Z. Three different techniques for administering analgesia during transrectal ultrasoundguided prostate biopsy: a comparative study. Int Braz J Urol 2012;38:122128.

21. Addla SK, Adeyoju AA, Wemyss-Holden GD, Neilson D. Local anaesthetic for transrectal ultrasound-guided prostate biopsy: a prospective, randomized, double blind, placebo-controlled study. Eur Urol 2003;43:441-443.

22. Hossack T, Woo HH. Acceptance of repeat transrectal ultrasonography guided prostate biopsies with local anaesthesia. BJU Int 2011;107 Suppl 3:38-42.

23. Nazir B. Pain during transrectal ultrasound-guided prostate biopsy and the role of periprostatic nerve block: what radiologists should know. Korean J Radiol 2014;15:543-553.

24. Khurana N, Lavania P, Goyal R, Agrawal S, Dubey D, Mandhani A, Srivastava A, Kapoor R, Kumar A. Apical block versus basolateral prostatic plexus block in transrectal ultrasound guided prostatic biopsy: A prospective randomized study. Indian J Urol 2006;22:118-121.
25. Turgut AT, Yılmaz Ö, Ölçücüoğlu E, Koşar P, GeyiK PÖ, Koşar U. Transrektal Ultrasonografi (TRUS) Eşliğinde Prostat Biyopsisinde Hasta Rahatsızığına İlişkin Risk Faktörlerinin Değerlendirilmesi. Sorumlu Yazı İşleri Müdürü: Prof Dr H Canan Hasanoğlu 2007;1:145-149.

26. Yun TJ, Lee HJ, Kim SH, Lee SE, Byun SS, Hong SK, Cho JY, Seong CK. Prospective analysis on the relation between pain and prostate volume during transrectal prostate biopsy. Korean J Radiol 2007;8:231-235.

27. Bingqian $L$, Peihuan $L$, Yudong $W$, Jinxing $W$, Zhiyong W. Intraprostatic local anesthesia with periprostatic nerve block for transrectal ultrasound guided prostate biopsy. J Urol 2009;182:479-484.

28. Giannarini $G$, Autorino $R$, Valent $F$, Mogorovich A, Manassero F, De Maria M, Morelli G, Barbone F, Di Lorenzo G, Selli C. Combination of perianalintrarectal lidocaine-prilocaine cream and periprostatic nerve block for pain control during transrectal ultrasound guided prostate biopsy: a randomized, controlled trial. J Urol 2009;181:585-593.

29. Aslan R, Erbin A, Celik S, Ucpinar B, Eryilmaz R, Taken K. Periprostatic nerve block alone versus combined with perineal pudendal nerve block or intrarectal local anesthesia during transrectal ultrasound-guided prostate biopsy: A prospective randomized controlled trial. Int J Urol 2019;26:833838. 